\title{
Determination of Acaricides in Honey by Solid-Phase Extraction and Gas Chromatography / Mass Spectrometry
}

\author{
Joo Yeon Hong, Ok-Sang Jung, ${ }^{\dagger}$ Jae Jeong Ryoo, ${ }^{\ddagger}$ and Jongki Hong ${ }^{*}$ \\ College of Pharmacy, Kung Hee Lniversin, Seoul 130-701. Korea. *E-mail. jhongiakhuac.hr \\ -Department of Chemistrv, Pusan National Dniversin, Pusan 609-735, Korea \\ $\ddagger$ Department of Chemistry Education, Kvingpook National Lniversity, Daegu $712-714$, Korea \\ Received Altgust 29, 2008, Accepted Kovember 3. 2008
}

\begin{abstract}
An analytical method based on solid-phase extraction and gas chromatography / mass spectrometry has been developed for measurenent of acaricides (amitraz, bromopropylate, coumaphos, cymiazole, and tetradifon) in honey sample. In the stability test of acaricides in honey, amitraz underwent a rapid degradation into 2,4-dimethylaniline (DMA), 2,4-dinethylphenylformanide (DMPF), and $N$-(2,4-dimethylphenyl)- $N$-methylformamidine (DMPMF), whileas other acaricides were found to be stable even for over three months. Extraction of five acaricides from $5 \mathrm{~g}$ of honey sample was carried out by liquid-liquid extraction using $20 \mathrm{~mL}$ of ethy lacetate. For purification, Flonisil-SPE cartridge with elution of $5 \mathrm{~mL}$ of $n$-hexane/ acetone $(55: 45, v / v)$ was found to remove interferences effectively. Quantification was performed using gas chromatography / mass spectrometry in the selected ion monitoring mode. Spiking experiments were carried out to determine the recovery, precision, and limits of detection (LODs) of the method. The overall recovery values from honey spiked at 0.02 and $0.20 \mathrm{~kg} / \mathrm{g}$ levels, respectively, were found to be greater than $75 \%$ for all acaricides. The method detection limits for acaricides were ranged from 0.1 to $3 \mathrm{ppb}$. The developed method in this study was applied for the monitoring of acaricides in honey products collected from urban markets in Korea.
\end{abstract}

Key Wond : Food analysis. Honey. Acaricides, Solid-phase extraction, GC/MS

\section{Introduction}

Acaricides have been widely used for the control of the honey bee parasite Varroa destructor. consequently leading to contamination of honey and other bee products. ${ }^{i}$ Recently. many countries have concerns of safety for human consumption with new nules and more stringent regulations in use of acaricides to honey. Considerable attention is focused on regulating the allowable limits for acaricide residues in honey ${ }^{3 / 5}$ Consequently, new analytical method is required to quantify acaricides used in Korea at low levels of concentration in honey and honeybee products.

In addition. some acaricides are unstable and are degraded in aqueous solution depending on the $\mathrm{pH}$ value. To verify the safety of honey and its related products, the stability test of acaricides should be performed in honey. Several results ${ }^{6-9}$ have been reported on the stability of chlorinated pesticides and phosphorus pesticides in honey and beeswax.

Several analytical methods have been reported for the measurement of pesticides to determine not only their presence but also their concentrations in honey' samples with high precision and accuracy. ${ }^{10.11}$ In particular, the analy sis of acaricides present at sub-nanogram levels in honey samples requires extensive sample extract clean-up procedures prior to their introduction into sensitive instruments. Moreover, the clean-up procedure for honey is complicated due to the coextraction of large quantities of sugar components and vitamines. In general. the sugar content of honey is about $80 \%$ of the net mass. ${ }^{12}$ and can significantly reduce the analytical performance of $\mathrm{GC} / \mathrm{MS}$ due to the accumulation of residues in the injection port. column and ion source. Several approaches ${ }^{13-15}$ have been developed to eliminate these co-extracted sugarinterferences. including liquid-liquid partitioning. gel pernea- tion chromatograply. conventional column cluromatography and multiple clean-up methods.

Liquid-liquid partition is conmonly used for pesticide residue analy sis. These techniques are time consuming and laborious and require to use a large amount of toxic organic solvent, whereby loss of analytes can be significant. Solid-phase extraction (SPE) ${ }^{16-18}$ has been previously used in analy sis of pesticide in honey, as well as solid-phase nucroextraction (SPME). ${ }^{19: 9}$ resulting in simple. efficient. and solvent-free methods. Recently. GC/MS combined with SPME has been increasingly used for the determination of pesticides in various samples due to its fast and easy sample preparation. ${ }^{3-\hat{-3}}$ As alternative method, high performance liquid chromatography-UV detection ${ }^{2-4}$ and mass spectrometro has also been popularly used for the analy sis of pesticides in honey and honeybee products. However. simultaneous determination of acaricides and anitraz-degrdation products allowed the limited use in Korea has not been studied in detail.

This paper presents a rapid and sensitive method for the simultaneous quantification and confirmation of 5 acaricides and amitraz-degrdation products in honey. cleaned by solidphase extraction and deternined by GC/MS-SIM mode. The developed method was validated by linearity recovery. method detection limits. and duplicate analysis. This method was applied to the analysis of pesticide residues in various types of honeyss marketed in Korea.

\section{Materials and Methods}

Materials and Standards. Amitraz, bromopropylate, coulmaphos. and tetradifon were purchased from ChemService (West Chester, PA, USA) and most of them were of $>99 \%$ certified purity. Cymiazole was obtained from KBNP 
<smiles>Cc1ccc([N+](=O)[O-])c(C)c1</smiles>

Dimethylaniline (DMA)

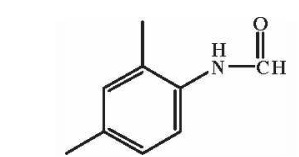

2.4-dimethylphenyl formamide (DMPF)<smiles>CNC=Nc1ccc(C)cc1C</smiles>

N-methyl-N" $N^{\prime}-(2,4-$ dinethylphenyl $)$ formanidine (D.MP.MF)<smiles>Cc1ccc(/N=c2\sccn2C)c(C)c1</smiles>

Cymiazole

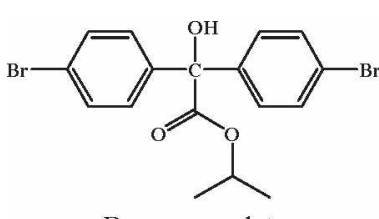

Bromopropylate

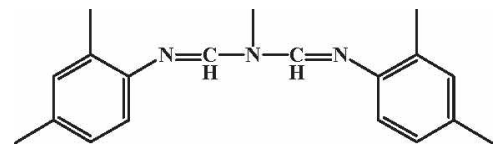

Annitraz

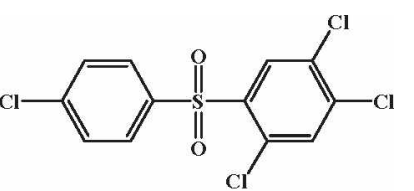

Tetradifon

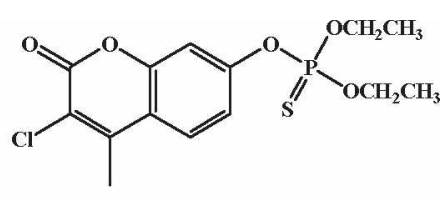

Coumaphos
Figure 1. Chemical struthures of acarieides and annitraz-degradation produets.

(Seoul. South Korea). The degradation products of amitraz, 2.4-dimethỵlaniline (DMA) and 2.4-dimethy lphenylformamide (DMPF) were purchased from Aldrich Chemical Co. (Milwaukee. WI. USA) and the other degradation product. N-(2.4-dimethyl-phenyl)- " $^{\prime}$-methyl formamidine (DMPMF) was purchased from Dr. Elurenstorfer (Augsburg. Germany). As internal standards phenanthrene- $d_{10}$ and ${ }^{13} \mathrm{C}_{6}$-hexachlorobenzene (HCB) were used and these were purchased from Cambridge Isotope Laboratories ${ }^{\text {Int }}$ (Frontage Road Andover. MA. USA). Figure 1 indicates the chemical structures of acaricides and degradation products of amitraz.

All organic solvents (acetone, $n$-hexane and ethylacetate) were of pesticide analysis grade and obtained from J. T. Baker (Phillipsburg. NJ. USA). Hỵdrochloric acid used for degradation test of amitraz was purchased from Merck (Danmstadt, Germany). Sodium hydroxide was purchased from Samchun pure chemical co. LTD (Gyeonggido. Korea). Anlyydrous $\mathrm{Na}_{2} \mathrm{SO}_{4}$ was purchased from Junsei (Tokyo, Japan) and used to eliminate water from the extract. Laboratory'distilled water was obtained from Milipore (Bedford. MA. USA).

Standard stock solutions of acaricides were prepared by dissolving $10 \mathrm{mg}$ of each compound in $50 \mathrm{~mL}$ of ethylacetate and stored at the refrigerator. Mixed compound calibration solutions were prepared from the stock solutions in 5, 20, 100 . 500 . and $1000 \mathrm{ppb}$ concentrations and used as spiking solutions as well. Stock standard and working solutions were stored at $+{ }^{\circ} \mathrm{C}$ and used for no longer than 3 months and 1 week. respectively.

Sample Extraction and Clean up. A $5 \mathrm{~g}$ amount of honey was dissolved in $5 \mathrm{~mL}$ of triply distilled water in a $100 \mathrm{~mL}$ beaker and homogenized by shaking with a glass stick. The

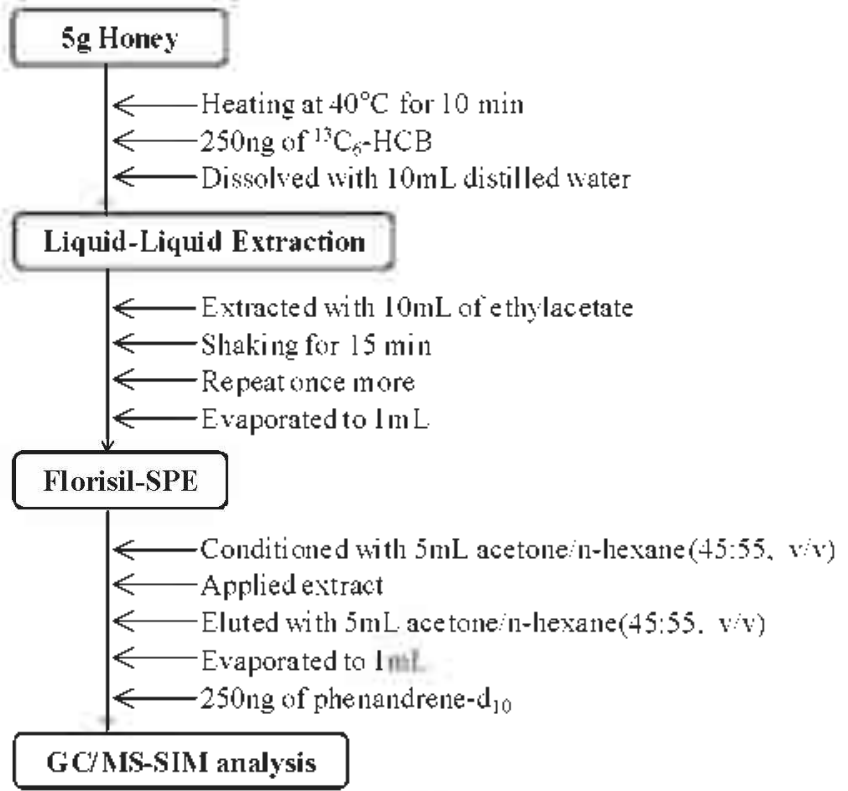

Figure 2. Analytical procedures for the determination of acaricides in honey samples.

addition of distilled water was used to reduce its viscosity and facilitate its handling. Homogenized honey was fortified with $100 \mu \mathrm{L}$ of standard mixture, to give final concentrations in the range of $0.02 \mu \mathrm{g} / \mathrm{g}$ and $0.2 \mu \mathrm{g} / \mathrm{g}$. After then. the sample was transferred into the separate funnel and nixed with $20 \mathrm{~mL}$ of ethyl acetate submitting it to extraction by shaking for $20 \mathrm{~min}$. Then the organic phase was collected. The sample was once again extracted as the above-described procedure. The two collected portions were combined and passed through the filter-paper filled with anhydrous $\mathrm{Na}_{2} \mathrm{SO}_{4}$ to elininate water in ethyl acetate. The solvent was evaporated in a rotary evaporator under reduced pressure and the sample was dried under a gentle stream of pure nitrogen. Finally, the residue was dissolved in $\operatorname{lmL}$ of ethylacetate.

For honey fortification, a certain amount of honey was heated in a water bath at $45^{\circ} \mathrm{C}$ for $20 \mathrm{~min}$, and left calm for 15 min for cooling. The fortified samples were prepared by adding an appropriate amount of the standard solution to the honey samples. The mixture was mechanically stirred in a blender, so as to ensure homogenization and then submitted to the extraction step.

Florisil and silica SPE cartridges were preconditioned by successive washing with $5 \mathrm{~mL}$ of acetone and $5 \mathrm{~mL}$ of acetone $/ n$-hexane $(45: 55 . \mathrm{v} / \mathrm{v})$. The extract was dissolved in $1 \mathrm{~mL}$ of ethyl acetate and transferred to the column. and the $100 \mathrm{~nL}$ beaker was washed with I $\mathrm{mL}$ of ethyl acetate. which was also transferred to the column. Acaricides retained on the surface of solid phase were eluted with $5 \mathrm{~mL}$ of acetone $/ n$-hexane. Columns were placed on a 12 -port vacuum manifold. and solvent was filtered and collected in $10 \mathrm{~mL}$ graduated tubes. A $100 \mu \mathrm{L}$ of the internal standard solution (phenanthrene-d $\mathrm{d}_{10 .}$. $0.05 \mathrm{lg} / \mathrm{g}$ ) was added to each sample, which was previously concentrated with a gentle stream of $\mathrm{N}_{2}$ gas. The purified solution was stored at $4^{\circ} \mathrm{C}$ until analyzed by GC/MS. Overall analytical procedure for the determination of acaricides is depicted in Figure 2. 
Degradation Test. The degradation test of acaricides was performed in honey. For this experiment. a $30 \mathrm{~g}$ of honey was heated in a water bath at $45^{\circ} \mathrm{C}$ for $20 \mathrm{~min}$. and left calm for 15 min for cooling. A $0.1 \mathrm{mg}$ of standard mixture was added to $5 \mathrm{~g}$ of honey sample. Spiked honey sample was fully mixed by a glass stick and put into a hood for inducing vaporization organic solvents in honey. The evaporated spiked samples were put in glass vials and $5 \mathrm{~g}$ of spiked honey was taken and extracted once a week for 4 weeks. The extracts were examined by GC/MS.

Method Validation. Validation of the analytical method for the four acaricides and DMA. amitraz-degrdation product. was determined by recovery. linearity. limit of detection (LOD), and limit of quantitation (LOQ).

For recovery validation, a standard solution containing the acaricides at concentrations of 0.02 and $0.2 \mathrm{\mu g} / \mathrm{g}$. respectively, was spiked into $5 \mathrm{~g}$ of honey. Spiked sample was extracted. purified and analyzed using the method described above.

For linearity validation the matrix spike was performed at five spiking levels (i.e., $0.005,0.02,0.1,0.5,1.0 \mathrm{fg} / \mathrm{g}$ ) for all compounds. Five calibration samples were injected in triplicate and five replicate analyses of the calibration solutions were performed. Calibration curves were constructed by linear regression of the peak area-ratios $(v)$ of each acaricide to internal standard. versus the concentration $(x)$ in $\mu \mathrm{g} / \mathrm{g}$.

Method detection limits (MDLs) were set as three times the standard deviation of the calculated concentration above the mean concentration determined in the blanks. The LOQ was defined as the concentration of standard solution with a $\mathrm{S} / \mathrm{N}>10$.

GC/MS Analysis. The sample analysis was carried out with an Agilent GC/MS (Palo Alto, CA. USA) equipped with DB-5MS fused-silica capillary column $(30 \mathrm{~m} \times 0.25 \mathrm{~mm}$ i.d. film thickness $0.25 \mathrm{am}$. J\&W Scientific. Folsom. CA. USA). Helium was used as a carrier gas at a flow rate of $1.0 \mathrm{~mL} / \mathrm{min}$. A $1 \mu \mathrm{L}$ sample was introduced by split injection mode (split ratio $10: 1$ ). The temperature conditions of the GC injection port and the MS interface were set at 280 and $300^{\circ} \mathrm{C}$ respectively. The oven temperature was held at $60^{\circ} \mathrm{C}$ for $1 \mathrm{~min}$. elevated to $200^{\circ} \mathrm{C}$ at $20^{\circ} \mathrm{Cmin}$. held at $200^{\circ} \mathrm{C}$ for 1 min. elevated from $200^{\circ} \mathrm{C}$ to $300^{\circ} \mathrm{C}$ at $8^{\circ} \mathrm{Cmin}$, and held for $5 \mathrm{~min}$.

The mass spectrometer was run in the electron ionization (EI) mode with an electron energy of $70 \mathrm{eV}$ and the electron

Table 1. Selected ions and retention times of acaricides used in GC/MS-SIM analysis

\begin{tabular}{|c|c|c|c|c|}
\hline & Compound & $\begin{array}{c}\mathrm{RT} \\
(\mathrm{min})\end{array}$ & $\begin{array}{c}\text { Quant. } \\
\text { Ion }(\mathrm{m} / \mathrm{z})\end{array}$ & $\begin{array}{l}\text { Confirm. } \\
\text { Ion }(\mathrm{m} / \mathrm{z})\end{array}$ \\
\hline Group I & LMA & 5.869 & 121 & 120 \\
\hline \multirow[t]{2}{*}{ Group II } & DMPF & 8.092 & 149 & 120 \\
\hline & DMPMF & 8.503 & 162 & 120 \\
\hline \multirow[t]{3}{*}{ Group III } & ${ }^{13} \mathrm{C}_{n}-\mathrm{HCB}$ & 9.976 & 290 & - \\
\hline & Phenanthrene- $d_{10}$ & 10.737 & 188 & - \\
\hline & Cymiazole & 11.628 & 218 & 185 \\
\hline \multirow[t]{4}{*}{ Group IV } & Bromopropylate & 17.305 & 341 & 339 \\
\hline & Tetradifon & 17.888 & 356 & 354 \\
\hline & Amitraz & 18.392 & 293 & 162 \\
\hline & Coumaphos & 19.532 & 362 & 364 \\
\hline
\end{tabular}

multiplier voltage was set at $1700 \mathrm{~V}$. The manifold temperature was maintained at $230^{\circ} \mathrm{C}$. The mass spectrometer was obtained in the mass range from 50 to $550 \mathrm{amu}$. For the monitoring and confirmation analysis, the selected ion monitoring (SIM) mode was used and the dwell time of each ion was set at $50 \mathrm{~ms}$. Selected ion groups in SIM mode are given in Table 1. All acaricides were identified by retention time and specific ions, and quantified by the internal standard method.

\section{Results And Discussion}

Degradation of Acaricides in Honey. The stability of amitraz. bromopropy late, cy miazol. and tetradifon was examined at room temperature for 4 weeks. For the elucidation of chemical structures of the degradation products. these acaricides were initially tested in acidic $(\mathrm{pH} 3)$ or basic $(\mathrm{pH} 12)$ aqueous solution for two days to be occurred rapidly decomposition and to minimize matrix interference. After standing spiked solution ( $5 \mathrm{mg}$ of acaricide in $10 \mathrm{~mL}$ ) at room temperature for 2 days, the resulting solution was extracted with ethylacetate and analy zed by GC/MS. Generally, most acaricides were stable under acidic aqueous conditions and no degradation was occurred at $\mathrm{pH} 3$. except for amitraz. However. bromopropylate under basic aqueous conditions was degraded by the hydrolysis procedure. This compound was slightly degraded into bis-(4-bromophenyl)methanol wia hydroxylation at the benzy lic position. Amitraz was unstable and rapidly degraded in acidic. basic and neutral media. The major degradation products of amitraz were 2.4-dimethylaniline (DMA). 2.4-dimethylphenylformanide (DMPF). and $N$-(2.t-dimethylphenyl)- ${ }^{\prime}$-methyl-formamidine (DMPMF). These degradation products were identified by comparison of their retention times and mass spectra with those of standards, (data not shown here).

The stability of amitraz, bromopropylate. cymiazol. and tetradifon in honey was also exanuned at room temperature for 4 weeks. Time profiles of degradation of amitraz (A). and of stability of bromopropylate, coumaphos. cymiazole. and tetradifon (B) in honey are presented in Figure 3. No significant degradation was observed for acaricides during all of the study period, except for amitraz. These phenomena were consistent with the results obtained in acidic aqueous sol-
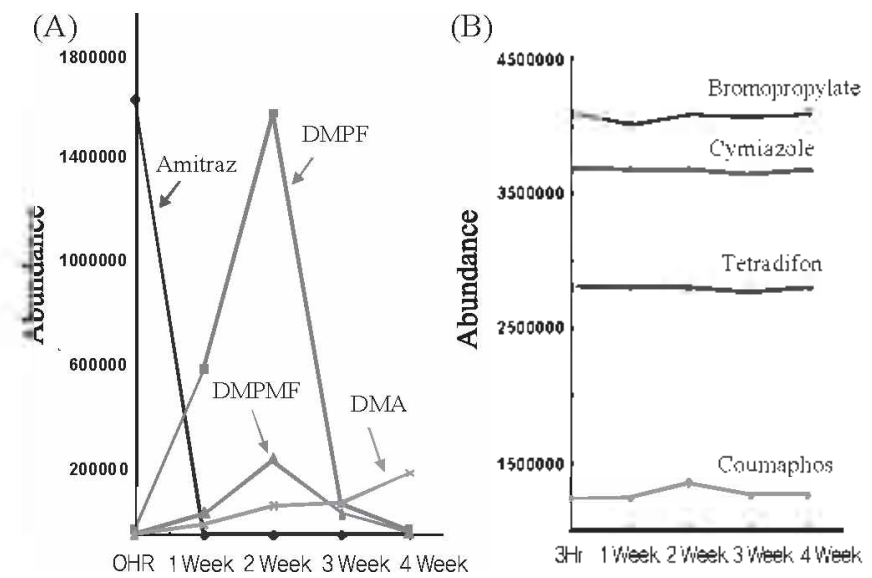

Figure 3. Time profiles of degradation of amitraz (A), and bromopropylate, coumaphos, crmiazole, and tetradifon $(B)$ in honey 
ution, since honey is slightly acidic media due to the presence of carbolydrates. The amitraz-spiked honey was extracted with ethylacetate and analyzed by GC/MS. Amitraz in honey was completely decomposed within 1 day and degraded into DMA. DMPF and DMPMF, which are identical products to those obtained in acidic aqueous solution. Among them, DMPMF and DMPF were observed as predominant products until 2 weeks. The formation of these compounds already was suggested as simple hydrolysis reaction at the amino group of amitraz. However the amounts of DMPF and DMPMF were exponentially decreased after 2 weeks and finally converted into DMA. Figure 4 shows degradation pathways of amitraz in honey. Therefore, for the monitoring of amitraz in honey. its degradation products instead of amitraz should be detected in GC/MS analysis

Extraction and Clean-up. The honey sample was dissolved with triply distilled water and extracted with a suitable solvent to remove the bulk of the sample matrix and extract the acaricide residue into the solvent. The selection of solvent can be critical for the satisfactory recovery of acaricides and anitraz-degradation products from the sample matrix. In this study, ethylacetate was used as the extraction solvent for the acaricide residue from the spiked honey sample. since ethylacetate has shown good solubility for acaricides used in this study, but less solubility for polar interferences such as glucoses. Under these extraction conditions. the overall extraction yield of acaricides was above $90 \%$, due to the good solubility of acricides in ethy lacetate.

During the extraction of the acaricides from the honey sample by liquid-liquid extraction method, several interferences including lipids pigment. carbohydrates as well as other extractable polar compounds in ethylacetate were co-extracted. although these compounds are less soluble in ethylacetate. Thus. it is difficult to pre-treat the sample extracts for the selective extraction of the acaricides, as well as to remove the interferences from the extract. Moreover. the presence of large amount of interferences can lead to adverse effects related to

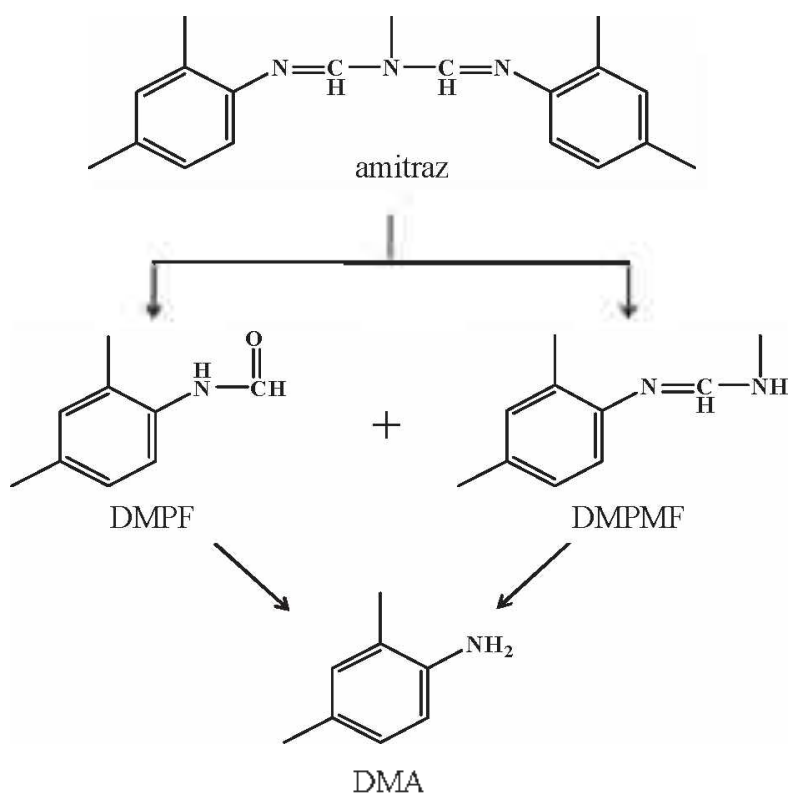

Figure 4. Degradation pathways of amitraz in honey false positive and inaccurate quantification. Therefore. several cleanup steps including solvent partitioning and column clean-up are required to remove interfering materials.

After liquid-liquid extraction, the extract still contained significant amount of the interferences: a maximum of a few mig per $5 \mathrm{~g}$ honey sample. In particular. nonpolar interferences are copresent in relatively high amounts compared with the sub-microgram levels of acaricides in ethylacetate. These compounds could interfere with acaricides in the GC/MS analysis. Therefore, an additional clean-up step was required to reach the sub- microgram level of quantification in the analysis of honey samples.

Florisil SPE cartridge ( $500 \mathrm{mg}, 6 \mathrm{~mL}$ ) was used for its convenience and simple clean-up method for the elimination of the remaining interferences in extract. The Florisil SPE-cartridge is known to effectively renove relatively polar interferences during the clean-up procedure. ${ }^{28}$ Figure 5 shows the elution patterns of acaricides and amitrazdegradation products with elution of acetone $/ n$-hexane $(v / N, 45: 55)$ on Florisil SPE cartridge. Most of the acaricides were eluted with $5 \mathrm{~mL}$ of the acetone $/ h$-hexane nixture elution on both cartridges. On the other hand. large amounts of interferences were coeluted on both cartridges when ethylacetate was used as the elution solvent. Non-polar solvents such as n-hexane and dichloromethane used as elution solvent resulted in a poor recovery for all acaricides on Florisil SPE-cartridge. Hence. the acetone/nhexane mixture was selected for SPE clean-up.

Method Application. Intental standards, acaricides, and amitraz-degradation products were spiked into the control honey sample, and then extracted. purified. and analyzed by the method developed. A trpical total ion chromatogram of the acaricides extracted from the spiked honey at + ppo level is given in Figure 6. No significant interferences near target analytes peaks were observed in the total ion chroma- togram. The ratios of the peak areas of acaricides and the corresponding internal standards were detennined.

Calibration equations. MDLs and recoveries of acaricides in honey sample are listed in Table 2 . The calibration curves were generated using a least-squares linear regression analysis ranging between 0.005 and $0.400 \mu \mathrm{g} / \mathrm{g}$. The correlation co-

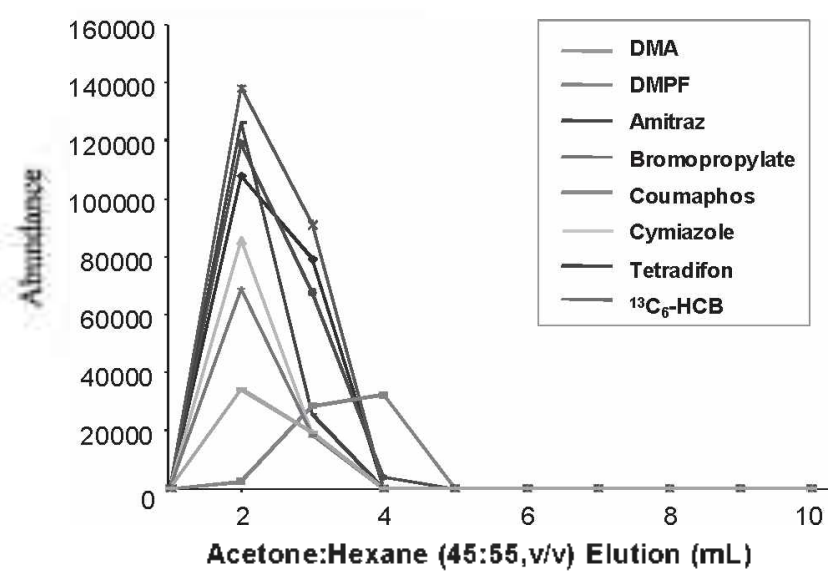

Figure 5. Elution patterns of acaricides and amitraz-degradation products on the Florisil cartridge with the elution of acetone/ $n$-hexane mixture $(\mathrm{v} / \mathrm{v}, 45.55)$ 


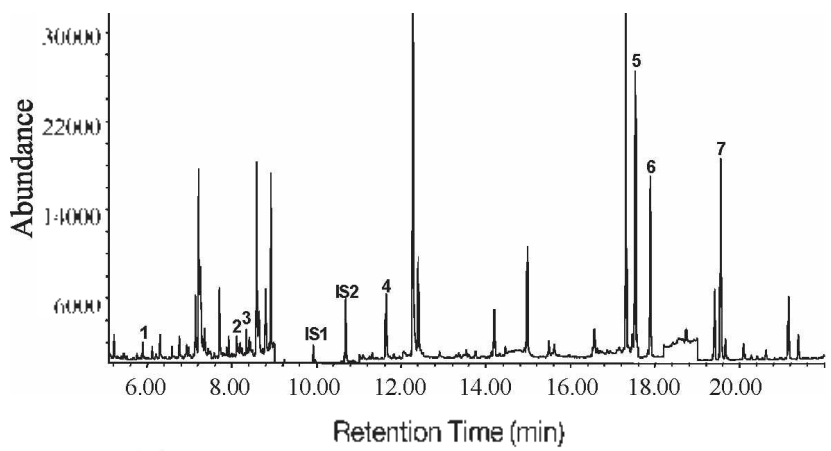

Figure 6. 'Jypical tolal ion chromatogram of the acaricides extracted from the spiked honer at 4 ppb level.

efficients for acaricides were higher than 0.991, except DMA, indicaling a good linearily.

Method detection limits (MDL) were determined as the lowest amount of analyte corresponding to a signal-to-noise ratio of 3 . In the GC/MS-SIM analysis, the base peaks of acaricides were used as the quantification ions for the lower detection limit. MDLs and recoveries were measured by analyzing seven replicate samples of $5 \mathrm{~g}$ control honey spiked with acaricides. The recovery of the acaricides ranged from 75.2 to $97.5 \%$, with relative standard deviations ( $R S D$ ) ranging lrom 4 to $10 \%$. The MDL is defined as the lowest concentration of acaricides which provide a greater than $99 \%$ confidence level when the procedure is used. MDLs of the five acancide compounds in the tested honey samples were within the range of 0.05-1.0 ng/g honey; however; these MDLs could be decreased by increasing the sample size and injection volume in the $\mathrm{GC}$ analysis. This ensures a reliable determination at low levels compared to other reports. ${ }^{1:-15}$
The proposed analytical procedure was used to determine the level of acaricides in honey collected from urban market. For the typical positive honey sample containing cymiazole $(0.8 \mu \mathrm{g} / \mathrm{g})$ and coumaphos $(2.28 \mu \mathrm{g} / \mathrm{g})$, the extracted ion chromatograms of cymiazole and coumaphos are shown in Figure 7. No significant interferences were observed in the ion chromatograms of cymiazole and coumaphos. To quantify these compounds, their base peaks were selected for the integration of the peak areas detected in the ion chromatograms. The detection and identification of other acaricides was achieved on the basis of retention times and selected ion ratios to the corresponding internal standard in the GC/MS-SIM.

\section{Conclusions}

The Florisil SPF. method combined with liquid-liquid extraction, was simple, consumed little organic solvent, and yielded satisfactory analytical results. Compared with other column clean-up methods for the removal of interferences from honey samples, the developed method had a higher sample throughput and better convenience in handling. Hence, the method can be used as a rapid screening tool for the determination of acaricides and amitraz-degradation products in honey products. The quantitation of acaricides was performed with precision and accuracy on the basis of GC/MS-SIM determination, showing within $10 \%$ of relative standard deviation and accuracy through spiking and recovery tests. Moreover, the analytical results, such as the recovery and method detection limit, were equivalent to or better than the official methods. ${ }^{25.29}$ Future work will explore the possibility of applying this method for the determination of pesticides in other types of honey and beeswax.

Table 2. Calibration equations. method detection limits (MDI.) and recorerics of acaricides in honers sample

\begin{tabular}{|c|c|c|c|c|c|c|}
\hline \multirow[b]{2}{*}{ Compound } & \multicolumn{3}{|c|}{ Regression line } & \multirow{2}{*}{$\begin{array}{l}\mathrm{MDL} \\
\text { (ng/g) }\end{array}$} & \multicolumn{2}{|c|}{ Recosen \pm R.S.D. $(\%)$} \\
\hline & Slope & Intercept & $\begin{array}{l}\text { Correlation } \\
\text { coefficient }\end{array}$ & & $20 \mathrm{ng} / \mathrm{g}$ & $200 \mathrm{ng} / \mathrm{g}$ \\
\hline DMA & 0.0015 & 0.0657 & 0.9849 & 1.0 & $84.6+10.12$ & $87.0+8.96$ \\
\hline Cymiarole & 0.1255 & -3.8211 & 0.9920 & 0.1 & $75.2 \perp 7.58$ & $91.2 \perp 6.38$ \\
\hline Bromopropylate & 0.1515 & -1.0736 & 0.9996 & 0.1 & $91.4 \pm 9.29$ & $95.3+6.19$ \\
\hline Telradilon & 0.0810 & -0.0749 & 0.9999 & 0.05 & $87.8+7.55$ & $92.0+5.35$ \\
\hline Coumaphos & 0.0856 & $-(1.8743$ & 0.9094 & 0.05 & $97.5+6.87$ & $96.4+4.15$ \\
\hline
\end{tabular}

(A)

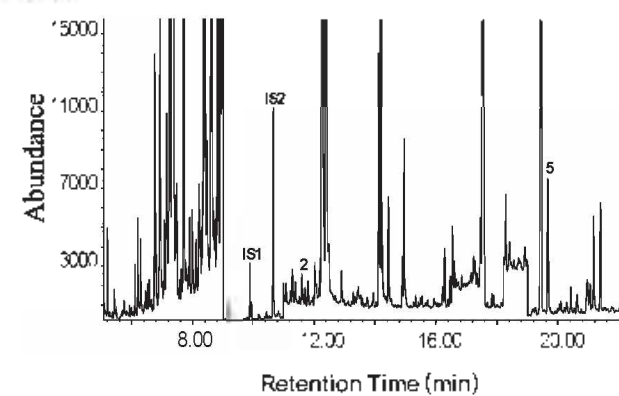

(B) Cymiarole
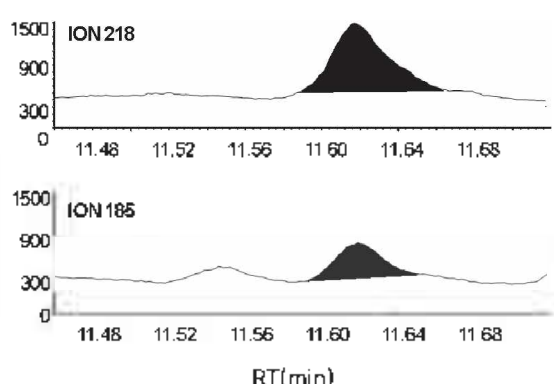

(C) Coumaphos
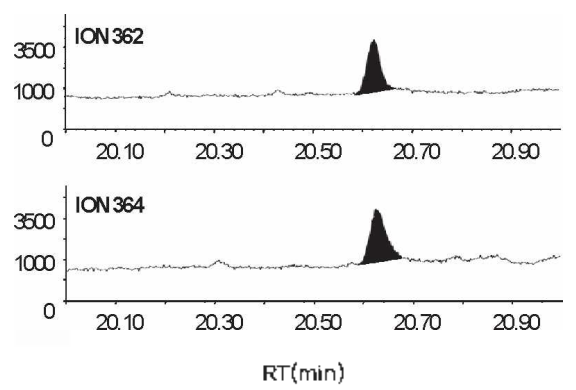

Figure 7. Total ion chromatogram (A) of purified extract from a positive hones sample and extracted ion chromatograms of crmiazole (B) and coumaphos (C) dececed by GC/MS-SIM. 
Aclonowledgments. This study was partially supported by the grants from the Korean Food and Dnig Administration and Seoul R\&BD Program (10524).

\section{References}

I. Femandez, M. A.; Sancho, M. T:: Simal, J.; Creus, T. M.; Huidobro, J. F.: Simal, I. J. Food Prot. 1997, 60, 78.

2. Femandez, M.; Pico, Y: Manes, T. J. Food Prot 2002, 65, 1502.

3. Rial-Otero, R: Gaspar, E. M: Moura, I: Capelo, T. L. Talanta $2007,71,1906$.

4 . council Regulation No. $2377 / 90 / \mathrm{EEC}$ of 26 June $1990 \mathrm{COJ}$ L 224 18.08.1990, p. 1) lqying down a community procedure for the establishment of maximum residue limits of veterinary medicinal products in foodstuffs of animal origin.

5. Food and Drug Administration of the United States, Pesticides Tolerances (heep://wwwefsan.fda.gov).

6. Martel, A. C.: Zeggane, S. J. Chromatogr \& 2002, 954, 173

7. Tunenez, I. J.: Bernal, I. L.; Toribio, L.: del Nozal, M. T.; Martū1, M. T. J. Chromatogr it 2002,946, 247 .

8. Tsigouri, A. D.; Menkissoglu-Spiroudi, U.; Thrasyvoulou, A. Pest Lanag Sci. 2001,57,467.

9. Timenez, J. J.; Bemal, J. L.; del Nozal, M. J.; Novo, M.; Higes, M.; Llorente, J. J. Chrontatogr: 4 2000, 871, 67.

10. Ryoo, T. T.; Kim, S. H.: Teong, Y. H: Do, H. S : Ryu, J. E: Kwon, H. Y. Teong, I. Y.; Park, H. T.; Lee, S. H.; Hong, M. K.; Hong, T. Bull. Korean Chent. Soc 2008, 29, 1043.

11. Tahboub, Y. R.; Zaater, M. F.; Bani, T. A. Anal. Chm Acta 2006, 558.62

12. Rissato, S. R: Galhiane, M. S: Knoll, F. R: Apon, B. M. $J$. Chromatogr it 2004, 1078, 153 .

13. Charlton, A. T, Ainsley, J. J. Chromatogr it 2007, 1111, 117 .
14. Konstantinos, S. L.: Pipina, A. S. Nikolaos, V. K. J. Chomatogr: A 2003, 996, 181 .

15. Hong, J.; Eo, Y.; Rhee, T.; Kim, T.; Kim, K. J. Chrontatogr: 1993. 639,261

16. Colin. M. E.: Bonmatin. I. M.: Moineaul. I.: Gaimon. C.: Brun. S.: Vermandere, J. P. Anch Environ. Contom. Toxicol 2004, 47, 387.

17. Harman. J. A.: Hapeman. C. J.: Mc Connell. L. L.: Potter. T. L.: Rice, C. P.; Sadeghi, A. M.; Smith, R. D.; Bialek, K.; Setton, K. A.; Schaffer. B. A.' Curry, R. J. Agric. Food Chent. 2005, 53, 6040.

18. Doran, G.; Helliwell, S.; Eberbach, P. J Assoc. Off Anal Chem. 2005, 88, 854

19. Kim, D. G.; Paeng, K. T: Cheong, C.; Hong, T. Anal. Sci. 2001, $17,53 \mathrm{~A}$.

20. Volante, M.: Cáttaneo, M.: Bianchi, M.; Zoccola, G. J. Environ. Sci. Health 1998. B33, 279

21. Fernandez, M. A.; Sancho, M. T:; Muniategui, S.; Huidobro, T. F. Lozano, J. J. Food Prot. $1995,58,449$

22. Volante, M.: Galarini, R.; Miano, V.: Cattaneo, M.; Pecorelli, I., Bianchi, M.: Marinoni, M. T.: Cossignani, L. Damiani, P. Chomatographia 2001, 5٪,241.

23. Arthur, C. L.; Pawliszyn, J. Anol. Chent 1990, 62, 2145.

24. Korta, E.; Bakkali, A.; Berrueta, I. A.; Gallo, B.; Vicente, F. J. Chomatogi 4 2001, 930, 21 .

25. Fenandez, M.; Pico, Y.: Gorotti, S: Manes, J. J. Agric. Food Chem 2001, 49,3540

26. Blasco, C.; Femandez, M.; Pena, A.; Lino, C.; Silveira, M. I.; Font G.; Pico, Y. J. Agric. Food Chem. 2003, 51, 8132.

27. Hong. J.: Kim. D.-G.: Palng. K. -I. I. Bull. Korean Chem. Soc. $2000,18,785$

28. Hong, J: Kim, H.-Y: Kim, D.-G.; Seo, T; Kim, K.-J. J. Chrontatogr . 4 2004, 1038, 27.

29. Korean Food \& Dnig Administration. Official Method No. 5-29-7: KFDA: Seoul, 2008. 